\title{
Research Paper: Investigating the Cocaine-induced Reduction of Potassium Current on the Generation of Action Potentials Using a Computational Model
}

\author{
Hadi Borjkhani $^{1}$ (D), Mehdi Borjkhani ${ }^{2 *}$ (D), Morteza A. Sharif ${ }^{2}$ (D) \\ 1. School of Engineering Sciences, University of Tehran, Tehran, Iran. \\ 2. Department of Electrical Engineering, School of Industrial Technologies, Urmia University of Technology, Urmia, Iran.
}

\begin{tabular}{|l|l|}
$\begin{array}{c}\text { Use yur devic to scan } \\
\text { and read the article online }\end{array}$ & $\begin{array}{l}\text { Crtation Borjkhani, H., Borjkhani, M., Sharif, A, M. (2021). Investigating the Cocaine-induced Reduction of Potassium Cur- } \\
\text { rent on the Generation of Action Potentials Using a Computational Model. Basic and Clinical Neuroscience, 13(1), 15-24. http:// } \\
\text { dx.doi.org/10.32598/bcn.2021.1150.2 }\end{array}$ \\
& doi http://dx.doi.org/10.32598/bcn.2021.1150.2
\end{tabular}

\section{(c) (1)}

Article info:

Received: 01 Aug 2019

First Revision: 03 Aug 2020

Accepted: 05 Aug 2020

Available Online: 01 Jan 2022

Keywords:

Addiction, Cocaine, Delayedrectifier potassium current, Computational model, Chaos

\begin{abstract}
Introduction: Drugs of abuse, such as cocaine, affect different brain regions and lead to pathological memories. These abnormal memories may occur due to changes in synaptic transmissions or variations in synaptic properties of neurons. It has been shown that cocaine inhibits delayed rectifying potassium currents in affected brain regions and can create pathological memories. This study investigates how the change in the conductance of delayed rectifying potassium channels can affect the produced action potentials using a computational model.

Methods: We present a computational model with different channels and receptors, including sodium, potassium, calcium, NMDARs, and AMPARs, which can produce burst-type action potentials. In the simulations, by changing the delayed rectifying potassium conductance bifurcation diagram is calculated.

Results: By decreasing the potassium current for a fixed stimulatory signal, burst-type action potentials can be generated. In the following and with a further reduction of potassium conductance, produced action potentials exhibit non-linear and even chaotic behaviors.

Conclusion: Results show that for a specific range of potassium conductance, a chaotic regime emerges in produced action potentials. These chaotic oscillations may play a role in inducing abnormal memories.
\end{abstract}




\section{Highlights}

- Cocaine consumption reduces the potassium current in affected cells.

- Decreasing the potassium currents elicits burst action potentials.

- Produced bursts might have chaotic behaviors.

- Chaotic oscillations might be related to the toxic effects of cocaine.

\section{Plain Language Summary}

Drugs of abuse such as cocaine can manipulate brain circuits and may form some pathological memories. These memories can lead to long-term addiction. Furthermore, these drugs also can have toxic effects on the cells. Researchers are looking for the mechanisms that can lead to abnormal memories and toxic effects of drugs. It seems that an efficient mechanism that can be used by drugs of abuse is the manipulation of potassium currents in the affected cells. Here, in a computational model, we have shown that changes in the conductance of delayed rectifying potassium channels can lead to nonlinear and even chaotic behaviors in the produced action potentials. These behaviors might have a role in drug toxic effects.

\section{Introduction}

ddiction is a chronic disease that has vari1 ous negative consequences. Cocaine consumption is one of the pervasive forms of addiction. The use of drugs, such as cocaine, can lead to maladaptive behavioral changes. Many researchers have shown that these changes are due to the intervention of drugs in the plasticity mechanism of the brain (Nestler, 2001; Kauer, \& Malenka, 2007; Lüscher 2013; Kutlu, \& Gould 2016; Borjkhani, Bahrami, \& Janahmadi, 2018; Borjkhani, et al., 2018; Preston, Brown, \& Wagner, 2019). Some researchers consider that drugs of abuse can form a pathological memory, called the memory of addiction (Boening 2001; Kelley 2004; Nestler, 2013).

Among the involvement of different brain regions in the addiction process, the hippocampus has an integral role in forming addiction memories and triggering relapse during withdrawal times (Caffino, et al., 2014,; Kutlu, \& Gould, 2016; Preston, et al. 2019). It has been shown both empirically and computationally that one reason for the formation of addiction memory is the increased excitability of neurons (Cohen, Doze, \& Madison, 1992; Kauer, \& Malenka 2007; Borjkhani, Mahdavi, \& Bahrami, 2014; van Huijstee \& Mansvelder 2015; Shukla, et al. 2017; Borjkhani, et al. 2018; Borjkhani, et al. 2018a; Borjkhani, et al. 2018b).
Excitability of the neurons can be changed by drug intervention in N-methyl-D-aspartate (NMDA) and $\alpha$-amino-3-hydroxy-5-methyl-4-isoxazolepropionic acid (AMPA) receptors mediated currents that some researchers investigated (Trujillo 2002; Bao, Kang et al., 2007; Kauer, \& Malenka 2007; Zweifel, Argilli, E., Bonci, \& Palmiter, 2008; Zachariou, Alexander, Coombes, \& Christodoulou2013; Borjkhani, et al. 2018; Borjkhani, et al. 2018). Meanwhile, the missing issue is the role of potassium currents in changing cell excitabilities. It has been observed that the consumption of cocaine increases the excitability of the hippocampal neurons by inhibiting the potassium current (Chen, Lin, Lin, \& Tsai, 2006). Cocaine consumption provokes action potential bursts in neurons (Chen, et al., 2006). Moreover, it has been suggested that the emergence of the burst is associated with cocaine's inhibitory effects on the delayed rectifying K current (Chen, et al., 2006). Therefore, one of the mechanisms by which cocaine changes neurons' excitabilities and innervates in memory formation is the reduction of potassium current. So, based on these observations, we want to computationally investigate potassium current reduction affects the produced action potentials in the hippocampus. This research can reveal new dimensions of the formation of cellular addiction.

In the next section, the implemented computational model is introduced. Then the simulation results are presented, and, finally, potential applications of the proposed model are discussed. 


\section{Methods}

To analyze the cocaine effects on action potential generation in hippocampal neurons, we used a modified version of the 'Hodgkin-Huxley style' formulation (Hodgkin \& Huxley, 1952). The equation denoting voltage variation of the neuron with ionic current equations is as follows:

1) $d v-d t=-\left(I_{N a}+I_{N a p}+I_{K d r}+I_{A}+I_{M}+I_{C a}+I_{C}+I_{s A H P}\right.$ $\left.+I_{L}\right)-I_{A M P A}-I_{N M D A}$

Here, $\mathrm{I}_{\mathrm{Na}}$ is the transient sodium current, $\mathrm{I}_{\mathrm{Nap}}$ denotes the persistent sodium current, $\mathrm{I}_{\mathrm{Kdr}}$ shows the delayed rectifier potassium current, $\mathrm{I}_{\mathrm{A}}$ demonstrates the A-type potassium current, $\mathrm{I}_{\mathrm{M}}$ exhibits the

muscarinic-sensitive potassium current, $\mathrm{I}_{\mathrm{Ca}}$ illustrates the High-voltage calcium current, $\mathrm{I}_{\mathrm{C}}$ describes the

fast calcium-activated potassium current, $\mathrm{I}_{\mathrm{sAHP}}$ displays the slow calcium-activated potassium current,

$I_{L}$ indicates the leak current, $I_{A M P A}$ represents the AMPAR mediated current, and $\mathrm{I}_{\mathrm{NMDA}}$ refers to the NMDAR mediated current.

Transient sodium current $\left(\mathrm{I}_{\mathrm{Na}_{\mathrm{a}}}\right)$ can be described using the following equations (Golomb, Yue, \& Yaari., 2006):

2) $I_{N a}(V, h)=35 * m_{\infty}^{3}(V) \cdot h(V-55)$

$m=m_{\infty}(V)$

$h=\begin{gathered}{\left[h_{\infty}(V)-h\right]} \\ h_{\infty}(V)\end{gathered} d \phi$

$d t \quad \tau$

$\tau_{h}(V)=0.1+0.75\left(1+\exp \left(-\frac{(V+40.5)}{-6}\right)\right)-1$

Here, $\mathrm{m}$ and $\mathrm{h}$ are gating variables and $\tau_{\mathrm{h}}$ is the time constant. Persistent sodium current can be described by the following equation (Golomb, et al., 2006):

$$
\text { 3) } I_{\text {Nap }}(V)=0.1 * p_{\infty}(V) .(V-55)
$$

The delayed rectifier potassium current $\left(\mathrm{I}_{\mathrm{Kdr}}\right)$ can be represented by the following equations (Golomb, et al., 2006):

$$
\text { 4) } I_{K d r}(V, n)=g_{K d r} n^{4}(V+90)
$$

$d t=\frac{\phi\left[n_{\infty}(V)-n\right]}{(V)} d n$

$\tau_{h}(V)=0.1+0.5\left(1+\exp \left(-\frac{(V+27)}{-15}\right)\right)^{-1}$

Here, ${ }^{n}$ is the gating variable and $\mathrm{g}_{\mathrm{Kdr}}=6 \mathrm{mS} / \mathrm{cm} 2$ is the default conductance of the channel. The A-type potassium current $\left(\mathrm{I}_{\mathrm{A}}\right)$ can be demonstrated by the following equations (Golomb, et al., 2006):

$$
I_{A}(V, b)=1 \cdot 4 * a_{\infty}^{2}(V) \cdot b \cdot(V+90)
$$

$a=a_{\infty}(V)$

$d t=\frac{\left[b_{\infty}(V)-b\right]}{15} d b$

The muscarinic-sensitive potassium current $\left(\mathrm{I}_{\mathrm{m}}\right)$ is denoted by the below equation (Golomb, et al., 2006):

$$
\begin{aligned}
& \text { 6) } I_{m}(V, z)=1 * z .(V+90) \\
& d t=\frac{\left[z_{\infty}(V)-z\right]}{1} d z
\end{aligned}
$$

The High-voltage calcium current $\left(\mathrm{I}_{\mathrm{Ca}}\right)$ can be shown by the following equation (Golomb, et al., 2006):

$$
\begin{aligned}
& \text { 7) } I_{C a}(V, r)=0.2 * r^{2} \cdot(V-120) \\
& d t=\frac{[r(V)-r]}{1} d r
\end{aligned}
$$

The fast calcium-activated potassium current $\left(\mathrm{I}_{\mathrm{C}}\right)$ is described by the following equation (Golomb, et al., 2006):

$$
\begin{aligned}
& \text { 8) } I_{C}(\mathrm{~V}, c)=10 * d_{\infty}\left(\left[\mathrm{Ca}^{2+}\right]_{i} c .(\mathrm{V}+90)\right. \\
& d t=\frac{\left[c_{\infty}(\mathrm{V})-c\right]}{3} d r \\
& d_{\infty}\left(\left[\mathrm{Ca}^{2+}\right]_{i}\right)=\left(1+6\left[\mathrm{Ca}^{2+}\right]_{i}\right)^{-1}
\end{aligned}
$$

Here $\left[\mathrm{Ca}^{2+}\right]_{\mathrm{j}}$ is the calcium concentration in the neuron; the slow calcium-activated potassium current $\left(\mathrm{I}_{\mathrm{sAHP}}\right)$ can be shown by this equation (Golomb, et al., 2006):

$$
\begin{aligned}
& \text { 9) } I_{\text {sAHP }}(V, q)=5 \cdot q \cdot(V+90) \\
& d t=\frac{\left[q_{\infty}\left(\left[\mathrm{Ca}^{2+}\right]_{i}\right)-q\right]}{450} d q \\
& q_{\infty}\left(\left[\mathrm{Ca}^{2+}\right]_{i}\right)=\left(1+2^{4}\left[\mathrm{Ca}^{2+}\right]_{i}^{4}\right)^{-1}
\end{aligned}
$$


The leak current $\left(\mathrm{I}_{\mathrm{L}}\right)$ can be represented by this formula (Golomb, et al., 2006):

$$
I_{L}=0.05 *(V+70)
$$

This equation can show the dynamics of calcium concentration inside the neuron:

11) $\mathrm{d}\left[{ }^{\mathrm{Ca}} \mathrm{dt}^{2+}\right]_{\mathrm{i}}=-0.13 \mathrm{I}_{\mathrm{Ca}}-0.012 \mathrm{I}_{\mathrm{NMDA}}-0.0012 \mathrm{I}_{\mathrm{AMAP}}-$ $\left[\mathrm{Ca}^{2+}\right]_{\mathrm{i}} / 13$

The AMPA current $\left(\mathrm{I}_{\mathrm{AMAP}}\right)$ is modeled by the following formula (Destexhe, Destexhe, Mainen, \& Sejnowski 1998; Borjkhani, et al., 2018):

$$
\text { 12) } I_{A M A P}=035 * m_{A M P A} *(V-55)
$$

$\mathrm{dm}_{\mathrm{AMPA}}$

$$
\mathrm{dt}=\alpha_{\mathrm{AMPA}} \cdot \mathrm{G}_{\mathrm{St}} \cdot\left(1-\mathrm{m}_{\mathrm{AMPA}}\right)-\beta_{\mathrm{AMPA}} \mathrm{m}_{\mathrm{AMPA}}
$$

, where $\mathrm{m}_{\mathrm{AMPA}}$ is the gating variable of the receptor, $\mathrm{a}_{\mathrm{AM}}$ ${ }_{\mathrm{PA}}=1.1 \mathrm{~m} M / \mathrm{ms}$ and $\beta_{\mathrm{AMPA}}=0.67 \mathrm{~m} M / \mathrm{ms}$ are the opening and closing rate of the receptor, respectively, and Gst is the synaptic glutamate or the stimulatory signal which activates the receptor.

The NMDA current $\left(\mathrm{I}_{\mathrm{NMDA}}\right)$ can be represented by the following formula (Destexhe, et al,, \& Sejnowski 1998; Borjkhani, et al., 2018):

$$
\begin{aligned}
& \text { 13) } I_{N M D A}=(1+g v d) \cdot m_{N M D A} \cdot M \cdot g(V-55) \\
& \mathrm{dm}_{\mathrm{NMDA}} \\
& d t=a_{N M D A} \cdot G_{S t}\left(1-m_{N M D A}\right)-\beta_{N M D A} m_{N M D A} \\
& M g=1 /\left(1+\left(-\frac{\left[M g^{2+}\right]_{0}}{3.75}\right) * \exp (-0.062 * V)\right) \\
& \mathrm{dg} \\
& d t=\left(k\left(V-V^{0}\right)-g_{V D}\right) / \tau g
\end{aligned}
$$

Here, $\mathrm{m}_{\mathrm{NMDA}}$ is the gating variable of the receptor, $\mathrm{Mg}$, denotes the dynamics for $\mathrm{Mg}^{2+}$ blocking of the receptor, $\left[\mathrm{Mg}^{2+}\right]_{0}=2 \mathrm{mM}$ is the concentration of $\mathrm{Mg}^{2+}$ in the extracellular fluid, $\mathrm{g}_{\mathrm{VD}}$ is the receptor's conductance dependent to the voltage, $\mathrm{k}=0.0007$ and $\mathrm{V}_{0}=-100 \mathrm{mv}$ are constants, and $\tau \mathrm{g}=0.05 \mathrm{~ms}$ is a time constant. $\alpha_{\mathrm{NMDA}}=$ $0.14 \mathrm{Mm} / \mathrm{ms}$ and $\beta_{\mathrm{NMDA}}=0.03 \mathrm{mM} / \mathrm{ms}$ are the opening and closing rates of the receptor.

The following formula can describe the activation function of gating variables in the equations:
14) $\mathrm{x} \infty\left(\mathrm{V}_{\text {post }}\right)=\left(1+\exp \left(-\left(\mathrm{V}-{ }_{\sigma x} \theta^{x}\right)\right)^{-1}\right.$

, where $\mathrm{x}$ can be replaced by $\mathrm{x}=\mathrm{m}, \mathrm{h}, \mathrm{n}, \mathrm{a}, \mathrm{b}, \mathrm{z}, p, r$, $c$, and the related parameters are $\theta_{m}=-30$ and $\sigma_{m}=9.5$, $\theta_{n}=-35$ and $\sigma_{n}=10, \theta_{\mathrm{h}}=-45$ and $\sigma_{\mathrm{h}}=-7, \theta_{a}=-50$ and $\sigma_{a}=20, \theta_{b}=-80$ and $\sigma_{b}=-6, \theta_{z}=-39$ and $\sigma_{z}=5$ , $\theta_{p}=-41$ and $\sigma_{p}=3, \theta_{r}=-20$ and $\sigma_{r}=10$, and finally $\theta_{c}=-30$ and $\sigma_{c}=7$.

Here the units for the voltages are millivolts.

\section{Results}

Simulation results are presented in this section. All simulations have been performed in Matlab 2018a software. A stimulatory signal (assumed to be the glutamate) with an amplitude of $0.1 \mathrm{mM}$ and a frequency of $10 \mathrm{~Hz}$ with a pulse duration of $10 \mathrm{~ms}$ affects the AMPARs and NMDARs ( $\mathrm{G}_{\mathrm{st}}$ in equations 12 and 13$)$. The stimulatory signal is shown in Figure 1.

Since cocaine dose-dependently attenuates the potassium current in empirical observations (Chen, et al., 2006), in the simulations, the conductance of potassium current gradually increases from 0 to 10 , and the bifurcation diagram is shown in Figure 2. Here, by changing the conductance, the peaks of the action potentials are calculated. Between 2 to 8 values of the delayed rectifier potassium conductance $\left(\mathrm{g}_{\mathrm{Kdr}}\right)$, the model has multistability, and the voltage has several peak values. These multi-peaks may represent a chaotic behavior. Further decrease of the conductance from 2 or increase of the conductance from 8 leads to semi-stable peak values for generated action potentials.

For further analysis, action potentials for different values of gkdr and their related phase spaces are calculated and represented through Figures 3-7. Phase spaces are calculated by plotting the $\mathrm{V}_{\mathrm{n}+1}$ against $\mathrm{V}_{\mathrm{n}}$.

Here $\mathrm{V}_{\mathrm{n}}$ and $\mathrm{V}_{\mathrm{n}+1}$ are the values of the action potentials at the time of $n$ and $n+1$, respectively. Figure 3 shows the produced action potentials and related phase space for $\mathrm{g}_{\mathrm{kdr}}=0.01$. It can be seen that regular spiking patterns exist, and reconstructed space denotes a limit cycle.

The left panel illustrates the produced action potentials, and the right panel the related phase space.

By increasing the conductance to 1 (Figure 4.), the firing frequency increases, and spiking patterns can be seen here. The produced action potentials follow the fre- 


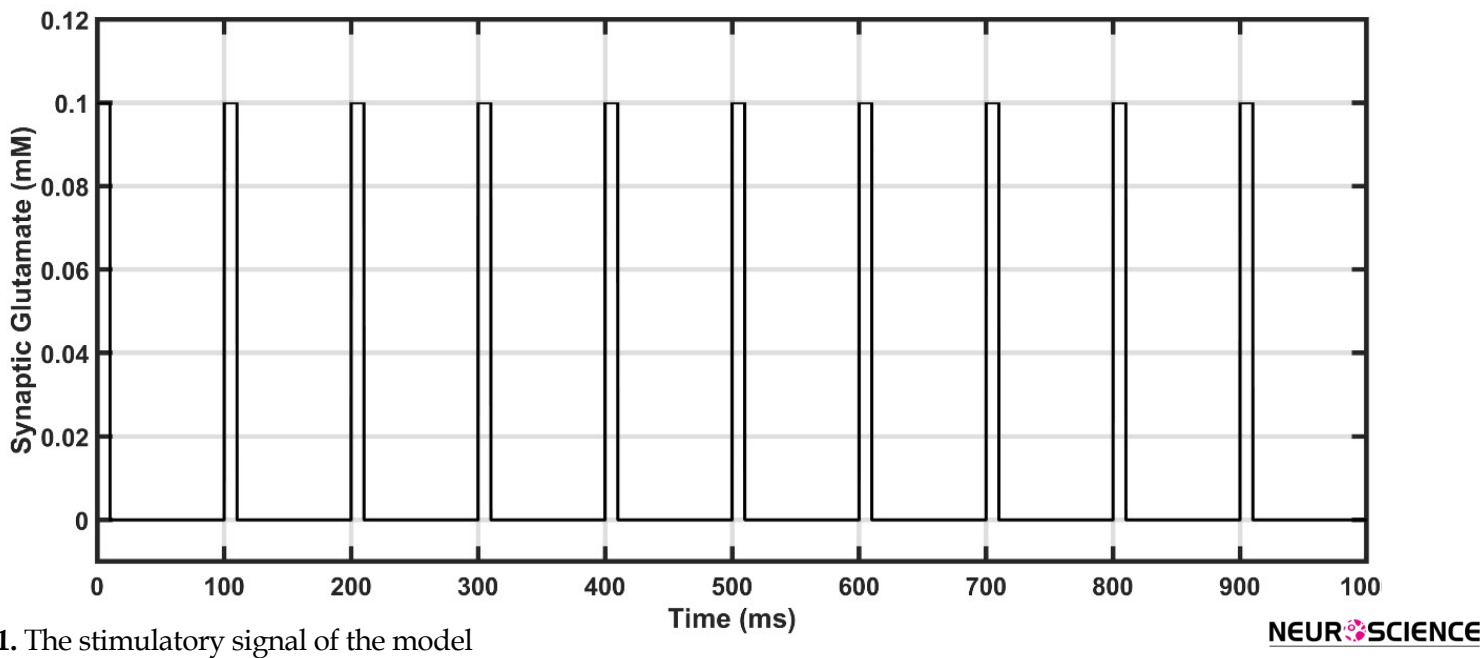

Figure 1. The stimulatory signal of the model

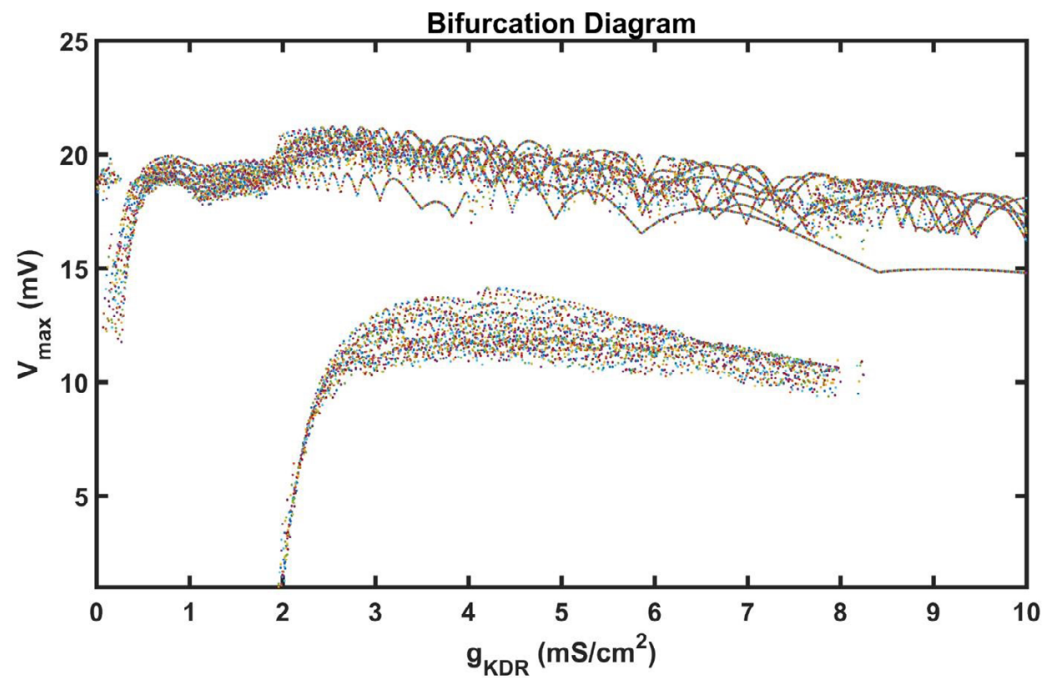

Figure 2. The peak values of the generated action potentials for different sets of $g_{\text {kde }}$ (bifurcation diagram)

NEUR SCIENCE
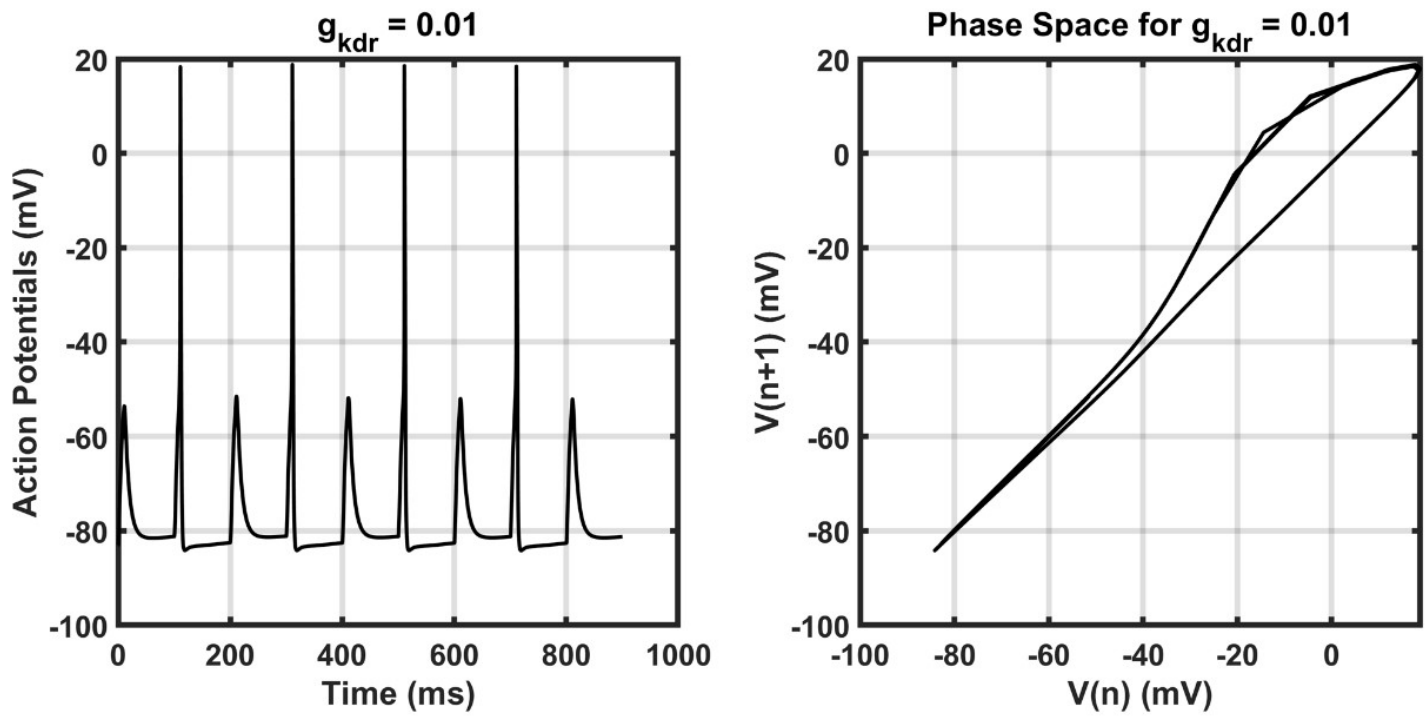

Figure 3. Produced action potentials and reconstructed phase space for $\mathrm{g}_{\mathrm{Kdr}}=0.01$ 

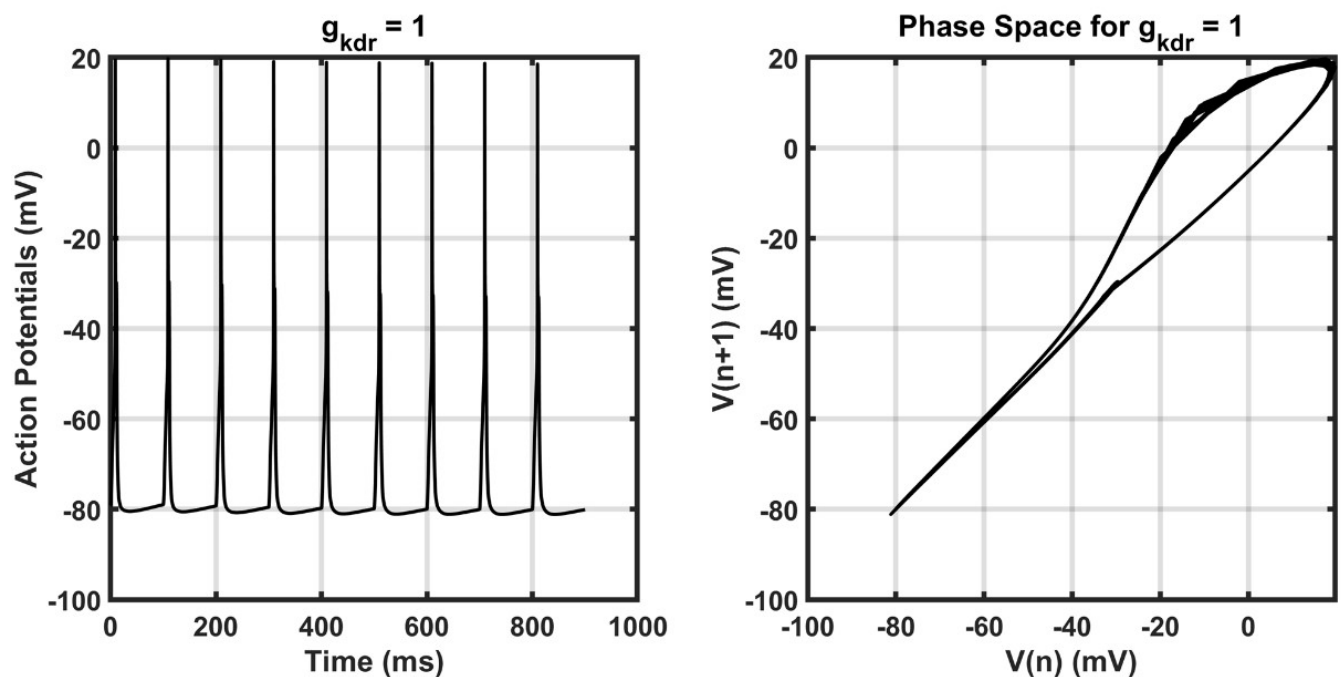

Figure 4. Produced action potentials and reconstructed phase space for $\mathrm{g}_{\mathrm{kdr}}=1$

NEUR SCIENCE

quency of the stimulatory signal. Furthermore, the phase space demonstrates a normal limit cycle.

The left panel denotes the produced action potentials, and the right panel shows the related phase space.

By changing the conductance to the $\mathrm{g}_{\mathrm{Kdr}}=4$, burst-type action potentials emerge (Figure 5). The reconstructed phase space of the signal shows that the chaotic regime appears. As seen, the generated potentials are different. Some of the potentials are single spikes, and some have burst. Also, the phase space shows that multiple limit cycles emerge that may show chaotic behaviors.

The left panel denotes the produced action potentials, and the right panel the related phase space.
By increasing the conductance $\left(\mathrm{g}_{\mathrm{kdr}}\right)$ to 6 , more irregularities emerge in the generated action potentials (Figure 6). These behaviors may represent chaotic behavior or may lead to chaos.

The left panel shows the produced action potentials, and the right panel the related phase space.

Figure 7 shows the action potentials and reconstructed phase space for $\mathrm{g}_{\mathrm{kdr}}=10$. It can be seen that chaotic oscillations diminish, and regular spiking patterns emerge again. In this case, we see the regular

The left panel denotes the produced action potentials, and the right panel the related phase space.
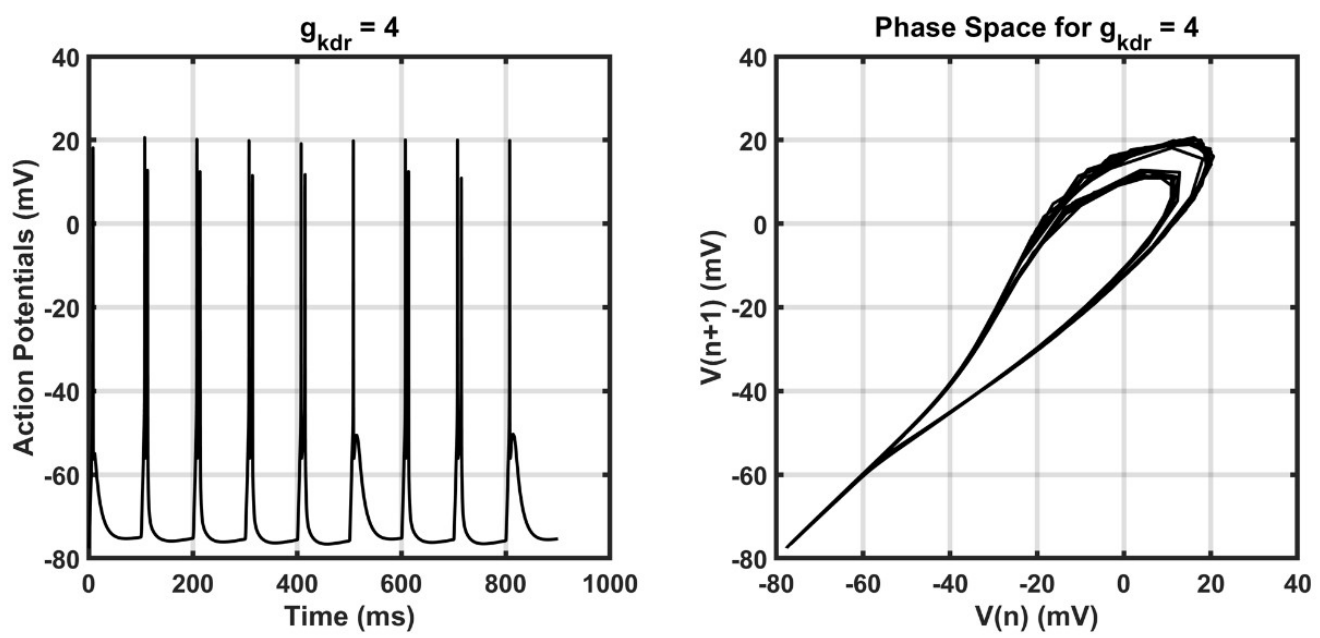

Figure 5. Produced action potentials and reconstructed phase space forg $\mathrm{kdr}_{\mathrm{dr}}=4$ 

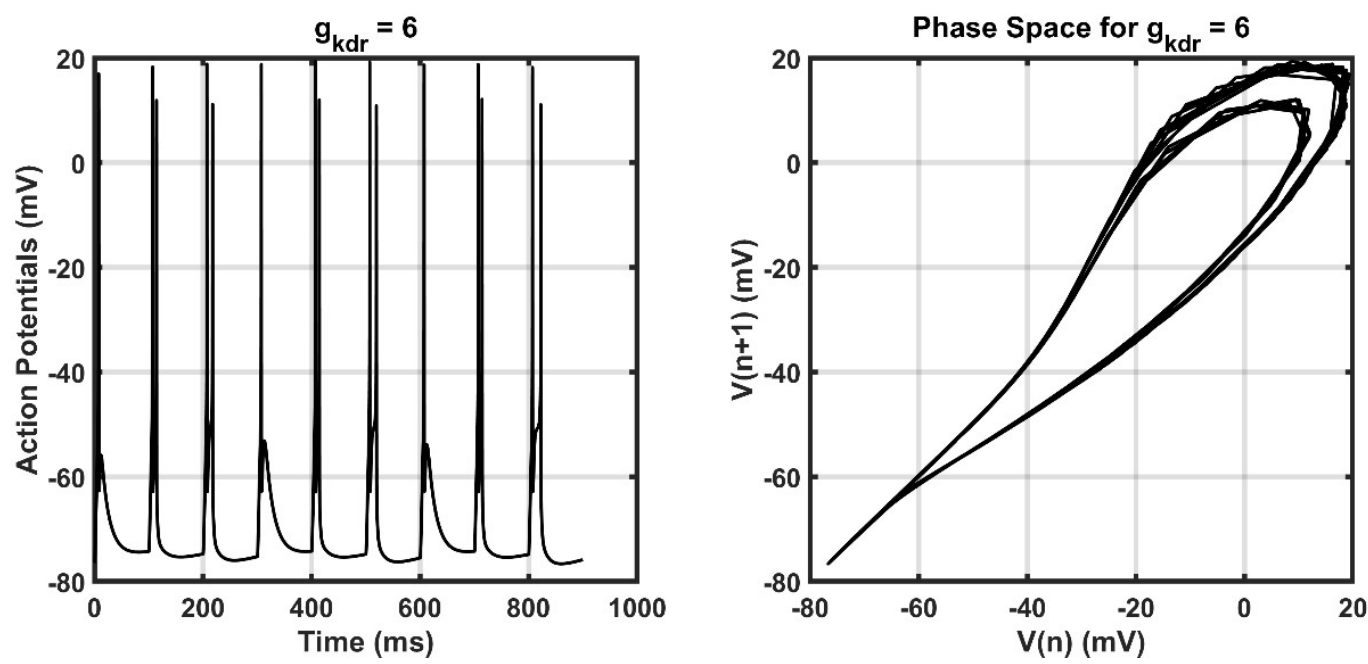

Figure 6. Produced action potentials and reconstructed phase space for $\mathrm{g}_{\mathrm{kdr}}=1$

NEUR:SCIENCE

\section{Discussion}

Despite many studies in addiction, lots of questions have remained unanswered. Cocaine interacts with several transporters, receptors, and channels (Kobayashi, Nishizawa, Iwamura, \& Ikeda, 2007). In this paper, the effect of reducing the conductivity of potassium channels (which can be due to the consumption of cocaine) in the generation of action potentials was investigated. For this purpose, a computational model was used that could generate the burst-type action potentials. The study of potassium current is critical because, in some experimental research, this current is affected by the consumption of cocaine. It has been shown that cocaine consumption blocks the calcium-dependent $\mathrm{K}+$ channel in the hippocampus neurons. Besides, it has been suggested that cocaine is related to the blocking of $\mathrm{Ca} 2+$-dependent $\mathrm{K}+$ channels that may broaden the action potential and cause repetitive firing of neurons (Premkumar, 2005). In addition to demonstrating this empirical finding using a computational model, we state that chaotic behaviors are also observed in the process of reducing potassium current. Besides that, decreasing the potassium currents in simulations elicits burst action potentials reported in empirical experiments (Chen, et al., 2006).

The simulation results show that by decreasing the potassium current for a fixed stimulatory signal, bursttype action potentials can be generated. With a further reduction of potassium conductance, produced action potentials exhibit non-linear and even chaotic behaviors. The appearance of chaotic patterns has been seen in many diseases and can contribute to forming abnormal and addictive memories, which requires further studies, both in computational and empirical research. The fact that cocaine inhibition of GIRK (the G protein-coupled
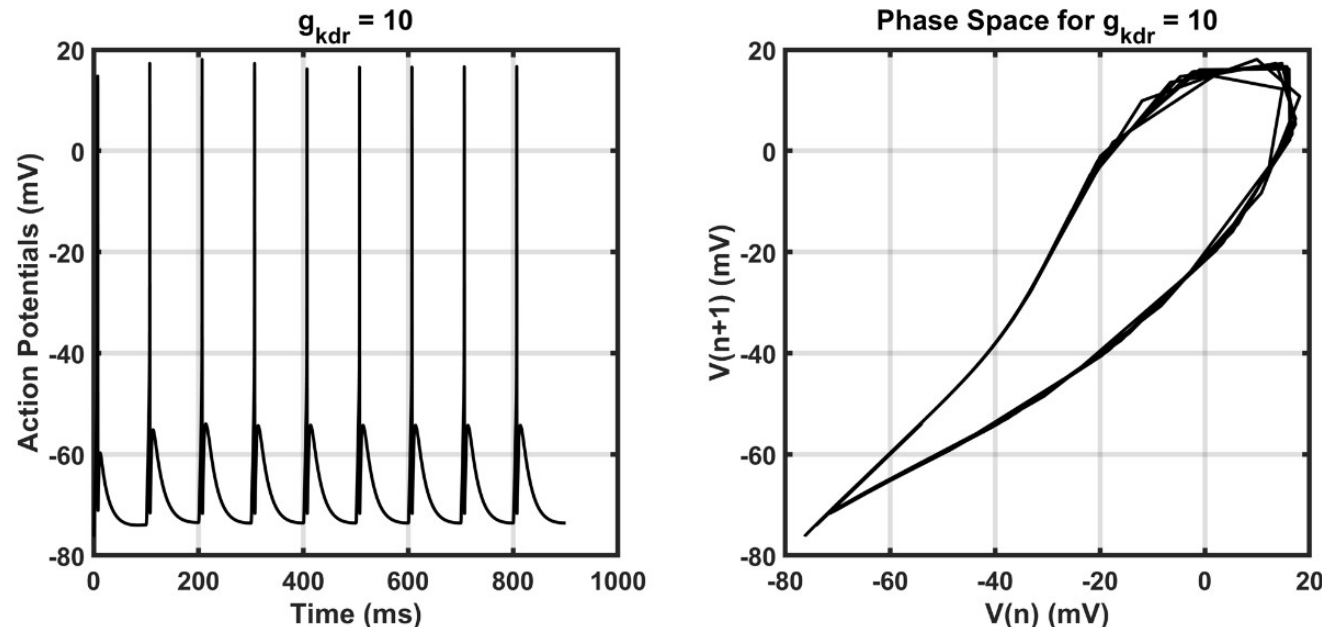

Figure 7. Produced action potentials and reconstructed phase space for $g_{\mathrm{kdr}}=10$ 
inwardly-rectifying potassium) channels may involve in its toxic effects (Kobayashi, et al., 2007) can relate to emerging chaotic oscillations which were observed in the simulations. Since cocaine has diverse harmful effects such as seizures, cardiac arrhythmias, and sudden death (Lathers, Tyau, Spino, \& Agarwal, 1988; O'leary and Hancox 2010), and the potassium channels play an essential role in creating these obstacles, the proposed model can help the researchers investigate these effects, too.

\section{Ethical Considerations}

\section{Compliance with ethical guidelines}

There is no related research's ethical considerations in the current research.

\section{Funding}

This research did not receive any grant from funding agencies in the public, commercial, or non-profit sectors.

\section{Authors' contributions}

All authors equally contributed to preparing this article.

\section{Conflict of interest}

The authors declared no conflicts of interest

\section{References}

Bao, G., Kang, L., Li, H., Li, Y., Pu, L., Xia, P., et al. (2007). Morphine and heroin differentially modulate in vivo hippocampal LTP in opiate-dependent rat. Neuropsychopharmacology, 32(8), 1738-49. [DOI:10.1038/sj.npp.1301308] [PMID]

Boening, J. (2001). Neurobiology of an addiction memory. Journal of Neural Transmission, 108(6), 755-65. [DOI:10.1007/ s007020170050] [PMID]

Borjkhani, M., Bahrami, F., \& Janahmadi, M. (2018). Assessing the effects of opioids on pathological memory by a computational model. Basic and Clinical Neuroscience, 9(4), 275-88. [DOI:10.32598/bcn.9.4.275] [PMID] [PMCID]

Borjkhani, M., Bahrami, F., \& Janahmadi, M. (2018a). Computational modeling of opioid-induced synaptic plasticity in hippocampus. PLoS One, 13(3), e0193410. [DOI:10.1371/journal. pone.0193410] [PMID] [PMCID]

Borjkhani, M., Bahrami, F., \& Janahmadi, M. (2018b). Formation of opioid-induced memory and its prevention: A computational study. Frontiers in Computational Neuroscience, 12, 63. [DOI:10.3389/fncom.2018.00063] [PMID] [PMCID]
Borjkhani, M., Mahdavi, A., \& Bahrami, F. (2014). A mathematical model for neuron astrocytes interactions in hippocampus during addiction. Paper presented at The 21th Iranian Conference on Biomedical Engineering (ICBME), Tehran, Iran, 26-28 November 2014. [DOI:10.1109/ICBME.2014.7043940]

Caffino, L., Frankowska, M., Giannotti, G., Miszkiel, J., Sadakierska-Chudy, A., Racagni, G., et al. (2014). “Cocaine-induced glutamate receptor trafficking is abrogated by extinction training in the rat hippocampus. Pharmacological Reports, 66(2), 198-204. [DOI:10.1016/j.pharep.2013.09.002] [PMID]

Chen, Y. H., Lin, C. H., Lin, P. L., \& Tsai, M. C. (2006). Cocaine elicits action potential bursts in a central snail neuron: The role of delayed rectifying K+ current. Neuroscience, 138(1), 257-80. [DOI:10.1016/j.neuroscience.2005.11.006] [PMID]

Cohen, G. A., Doze, V. A., \& Madison, D. V. (1992). Opioid inhibition of GABA release from presynaptic terminals of rat hippocampal interneurons. Neuron, 9(2), 325-35. [DOI:10.1016/0896-6273(92)90171-9]

Destexhe, A., Mainen, Z. F., \& Sejnowski, T. J. (1998). Kinetic models of synaptic transmission. Methods in Neuronal Modeling, 2, 1-25. http://citeseerx.ist.psu.edu/viewdoc/downloa $\mathrm{d}$ ?doi=10.1.1.219.3728\&rep=rep1\&type $=$ pdf

Golomb, D., Yue, C., \& Yaari, Y. (2006). Contribution of persistent $\mathrm{Na}+$ current and M-type $\mathrm{K}+$ current to somatic bursting in CA1 pyramidal cells: Combined experimental and modeling study. Journal of Neurophysiology, 96(4), 1912-26. [DOI:10.1152/jn.00205.2006] [PMID]

Hodgkin, A. L., \& Huxley, A. F. (1952). A quantitative description of membrane current and its application to conduction and excitation in nerve. The Journal of Physiology, 117(4), 500-44. [DOI:10.1113/jphysiol.1952.sp004764] [PMID] [PMCID]

Kauer, J. A., \& Malenka, R. C. (2007). Synaptic plasticity and addiction. Nature Reviews Neuroscience, 8(11), 844-58. [DOI:10.1038/nrn2234] [PMID]

Kelley, A. E. (2004). Memory and addiction: Shared neural circuitry and molecular mechanisms. Neuron, 44(1), 161-79. [DOI:10.1016/j.neuron.2004.09.016] [PMID]

Kobayashi, T., Nishizawa, D., Iwamura, T., \& Ikeda, K. (2007). Inhibition by cocaine of $\mathrm{G}$ protein-activated inwardly rectifying $\mathrm{K}+$ channels expressed in Xenopus oocytes. Toxicology in Vitro, 21(4), 656-64. [DOI:10.1016/j.tiv.2007.01.009] [PMID]

Kutlu, M. G., \& Gould, T. J. (2016). Effects of drugs of abuse on hippocampal plasticity and hippocampus-dependent learning and memory: Contributions to development and maintenance of addiction. Learning \& Memory, 23(10), 515-33. [DOI:10.1101/lm.042192.116] [PMID] [PMCID]

Lathers, C. M., Tyau, L. S., Spino, M. M., \& Agarwal, I. (1988) Cocaine-induced seizures, arrhythmias and sudden death. The Journal of Clinical Pharmacology, 28(7), 584-93. [DOI:10.1002/j.1552-4604.1988.tb03181.x] [PMID]

Lüscher, C. (2013). Drug-evoked synaptic plasticity causing addictive behavior. The Journal of Neuroscience, 33(45): 17641 6. [DOI:10.1523/JNEUROSCI.3406-13.2013] [PMID] [PMCID]

Nestler, E. J. (2001). Molecular basis of long-term plasticity underlying addiction. Nature Reviews Neuroscience, 2(2), 11928. [DOI:10.1038/35053570] [PMID] 
Nestler, E. J. (2013). Cellular basis of memory for addiction. Dialogues in Clinical Neuroscience, 15(4), 431-43. [DOI:10.31887/ DCNS.2013.15.4/enestler] [PMID] [PMCID]

O'leary, M. E., \& Hancox, J. C. (2010). Role of voltage-gated sodium, potassium and calcium channels in the development of cocaine-associated cardiac arrhythmias. British Journal of Clinical Pharmacology, 69(5), 427-42. [DOI:10.1111/j.13652125.2010.03629.x] [PMID] [PMCID]

Premkumar, L. (2005). Block of a Ca 2+-activated potassium channel by cocaine. The Journal of Membrane Biology, 204(3), 129-36. [DOI:10.1007/s00232-005-0755-6] [PMID]

Preston, C. J., Brown, K. A., \& Wagner, J. J. (2019). Cocaine conditioning induces persisting changes in ventral hippocampus synaptic transmission, long-term potentiation, and radial arm maze performance in the mouse. Neuropharmacology, 150, 27-37. [DOI:10.1016/j.neuropharm.2019.02.033] [PMID]

Shukla, A., Beroun, A., Panopoulou, M., Neumann, P. A., Grant, S. G., Olive, M. F., et al. (2017). Calcium permeable AMPA receptors and silent synapses in cocaine conditioned place preference. The EMBO Journal, 36(4), 458-74. [DOI:10.15252/ embj.201695465] [PMID] [PMCID]

Trujillo, K. A. (2002). The neurobiology of opiate tolerance, dependence and sensitization: Mechanisms of NMDA receptordependent synaptic plasticity. Neurotoxicity Research, 4(4), 373-91. [DOI:10.1080/10298420290023954] [PMID]

van Huijstee, A. N., \& Mansvelder, H. D. (2015). Glutamatergic synaptic plasticity in the mesocorticolimbic system in addiction. Frontiers in Cellular Neuroscience, 8, 466. [DOI:10.3389/ fncel.2014.00466] [PMID] [PMCID]

Zachariou, M., Alexander, S. P., Coombes, S., \& Christodoulou, C. (2013). A biophysical model of endocannabinoid-mediated short term depression in hippocampal inhibition. PloS One, 8(3), e58926. [DOI:10.1371/journal.pone.0058926] [PMID] [PMCID]

Zweifel, L. S., Argilli, E., Bonci, A., \& Palmiter, R. D. (2008). Role of NMDA receptors in dopamine neurons for plasticity and addictive behaviors. Neuron, 59(3), 486-96. [DOI:10.1016/j. neuron.2008.05.028] [PMID] [PMCID] 
This Page Intentionally Left Blank 